\title{
Clinical Study \\ Retrospective Analysis on the Gallstone Disease after Gastrectomy for Gastric Cancer
}

\author{
Kyong-Hwa Jun, ${ }^{1}$ Ji-Hyun Kim, ${ }^{1}$ Jin-Jo Kim, ${ }^{2}$ Hyung-Min Chin, ${ }^{1}$ and Seung-Man Park ${ }^{2}$ \\ ${ }^{1}$ Department of Surgery, St. Vincent's Hospital, College of Medicine, The Catholic University of Korea, Seoul 442-723, Republic of Korea \\ ${ }^{2}$ Department of Surgery, Incheon St. Mary's Hospital, College of Medicine, The Catholic University of Korea, \\ Seoul 403-720, Republic of Korea
}

Correspondence should be addressed to Seung-Man Park; parksm@catholic.ac.kr

Received 19 September 2014; Revised 14 May 2015; Accepted 21 May 2015

Academic Editor: Giovanni D. De Palma

Copyright (C) 2015 Kyong-Hwa Jun et al. This is an open access article distributed under the Creative Commons Attribution License, which permits unrestricted use, distribution, and reproduction in any medium, provided the original work is properly cited.

\begin{abstract}
Background. The aim of this study is to evaluate the incidence of gallstone after gastrectomy, risk factors for gallstone formation, and the surgical outcome of cholecystectomy after gastrectomy. Methods. A total of 2480 gastric cancer patients who underwent curative resection at two institutions between January 1997 and December 2012 were retrospectively reviewed. The patients' age, gender, diabetes mellitus, type of gastrectomy, extent of node dissection, and type of reconstruction were evaluated. Results. Gallstone formation occurred in 128 of 2480 (5.2\%) patients who had undergone gastrectomy for gastric cancer. The incidence of gallstones was significantly higher after total compared with subtotal gastrectomy. Roux-en-Y reconstruction and lymph node dissection in the hepatoduodenal ligament were associated with a significantly higher incidence. In multivariate analysis, diabetes mellitus and reconstruction method were identified as significant risk factors for gallstone development. The proportion of silent stone was higher in the laparoscopic cholecystectomy (LC) group than in the open cholecystectomy (OC) group. Operation time and hospital stay were shorter in the LC group than in the OC group. Conclusions. Diabetes mellitus and Roux-en-Y reconstruction are risk factors for gallstones after gastrectomy. Only a few postoperative complications after subsequent cholecystectomy occurred, even when using a laparoscopic approach.
\end{abstract}

\section{Introduction}

The incidence of gallstones is known to be high in patients who have undergone gastrectomy [1-5]. The underlying pathophysiology of this phenomenon includes resection of the anterior hepatic branch of the vagal nerve, nonphysiological reconstruction of the gastrointestinal tract, and altered response to and secretion of cholecystokinin $[4,6$, 7]. Subsequent cholecystectomy after gastrectomy is challenging because of adhesion around Calot's triangle, chronic nutritional insufficiency, and intestinal reconstruction that interferes with access to the common bile duct (CBD). The higher incidence of gallstones and surgical obstacles have led to a randomized multicenter controlled trial, known as the Cholegas study, in which prophylactic cholecystectomy during gastrectomy for cancer was not found to increase the risk of perioperative morbidity, mortality, or cost [8].
However, not all patients with gallstones develop gallstonerelated symptoms or require additional surgical treatments, and subsequent cholecystectomy using either an open or laparoscopic technique is feasible even in those patients who have undergone previous gastrectomy $[1,2,9,10]$. Moreover, the current consensus recommends that only patients with symptomatic gallstones should undergo cholecystectomy, because asymptomatic patients rarely develop serious biliary complications $[11,12]$. There have been several studies evaluating cholecystectomy in patients with a history of gastrectomy $[1,3,5,9]$; however, few studies with sufficient data are available about risk factors for gallstone after gastrectomy and the surgical outcomes following cholecystectomy for gallstone disease.

In this study, we analyzed the incidence of gallstone formation after gastrectomy, the interval between gastrectomy and diagnosis of a gallstone, and risk factors for gallstone 


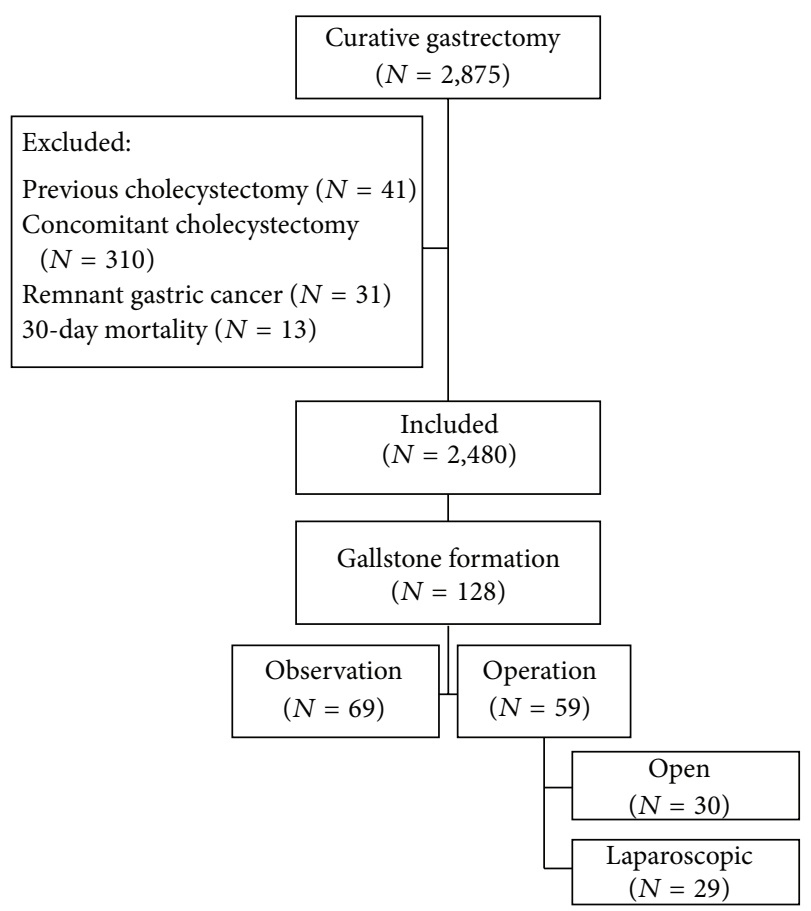

FIGURE 1: Patient enrollment and outcomes.

development. We also explored the surgical outcomes following cholecystectomy according to the surgical approach.

\section{Methods}

2.1. Patients. We enrolled 2875 patients who underwent curative gastric cancer surgery at the Department of Surgery, Incheon St. Mary's Hospital and St. Vincent's Hospital, The Catholic University of Korea between January 1997 and December 2012. Exclusion criteria were (1) previous cholecystectomy $(n=41)$, (2) prophylactic cholecystectomy $(n=$ $310)$, (3) remnant gastric cancer $(n=31)$, and (4) mortality within 30 days after surgery $(n=13)$ (Figure 1). After applying these criteria, a total of 2480 patients were included in this study. All 2480 cases involved either total gastrectomy or distal gastrectomy associated with systemic lymph node dissection. Open gastrectomy was performed in 1488 cases and laparoscopic gastrectomy was performed in 992 cases. Lymph node dissection and TNM staging were performed following the guidelines of the Japanese Research Society for Gastric Cancer (JRSGC) [13]. Every patient underwent vagotomy associated with gastrectomy and lymph node dissection. Intestinal reconstruction was performed using Roux-en-Y method for total gastrectomy and Billroth I or II anastomosis or Roux-en-Y reconstruction for distal gastrectomy. The patients were followed for a median of 91.6 (range, 15-206) months. Data from these patients were entered into a prospectively maintained database. The Institutional Review Boards of Incheon St. Mary's Hospital (OC14RIMI0034) and St. Vincent's Hospital (VC14RIMI0046) approved the study protocol.
The patients were followed up with an abdominal computed tomography (CT) scan every 6 months for 2 years after gastrectomy, every year for up to 5 years, and then every year until the end of the study period or death. The primary objective of such examinations was the detection of metastatic disease, but gallbladder information was recorded in every examination. Ultrasound examination was also performed if gallstone disease was detected by abdominal $\mathrm{CT}$ or if biliary pain occurred. Indications for surgery were biliary pain and biliary complications, such as acute cholecystitis, choledocholithiasis, cholangitis, or pancreatitis. Cholecystectomy was performed whenever the indications for surgery were appropriate or when patients with silent gallstone disease requested surgery using either an open or laparoscopic surgical approach.

The patients were classified into two subgroups: stone negative (SN, $n=2352$ ) and stone positive (SP, $n=128)$. The incidence of gallstone formation after gastrectomy for gastric cancer and the influence of clinical and surgical factors on stone formation were analyzed. The open cholecystectomy (OC) and laparoscopic cholecystectomy (LC) groups were also retrospectively compared with respect to the interval between gastrectomy and detection of a gallstone, the duration between detection of gallstones and cholecystectomy, indication of surgery, operation time, blood loss, postoperative complications, and hospital stay.

2.2. Statistics. Continuous variables were presented as means and standard deviations, while categorical variables were presented as frequencies and percentages. Fisher's exact test was used to compare differences in discrete or categorical variables, and the Mann-Whitney test was used for continuous variables. The cumulative incidence of gallstones after gastrectomy was evaluated by the Kaplan-Meier method and differences between groups were evaluated by the log rank test. Multivariate analysis with Cox proportional hazards model was used to compare the influence of each type of lymph node dissection and the type of reconstruction performed. Differences were considered statistically significant when the $P$ value was $<0.05$. Statistical analysis was done using SPSS version 20 (SPSS, Chicago, IL, USA).

\section{Results}

3.1. Demographic Data of Gastric Cancer Patients Who Underwent Curative Resection. The characteristics of 2480 patients are summarized in Table 1. One hundred twentyeight patients were diagnosed with gallstones. The incidence of gallstones at 5 and 10 years after gastrectomy was 11.4 and 19.1 percent, respectively (Figure 2). The interval between gastrectomy and diagnosis of gallstones was 45.9 months (range 1-149 months). Ninety-three of the 128 cases $(72.7 \%)$ were diagnosed within 5 years after gastrectomy. The age of the 2352 patients (1554 men and 798 women) in the stone negative $(\mathrm{SN})$ group was $59.9 \pm 11.7$ years and that of the 128 patients ( 80 men and 48 women) in the stone positive (SP) group was $60.6 \pm 12.9$ years. There were no significant differences in age $(P=0.539)$, gender $(P=$ $0.407)$, BMI $(P=0.663)$, or diabetes mellitus $(P=0.095)$ 
TABLE 1: Characteristics of the 2480 patients.

\begin{tabular}{|c|c|c|c|}
\hline & $\begin{array}{l}\text { Stone negative after gastrectomy } \\
\qquad(n=2,352)\end{array}$ & $\begin{array}{l}\text { Stone positive after gastrectomy } \\
\qquad(n=128)\end{array}$ & $P$ value \\
\hline Age & $59.9 \pm 11.7$ & $60.6 \pm 12.9$ & 0.539 \\
\hline \multicolumn{4}{|l|}{ Gender } \\
\hline Male & $1554(66.1)$ & $80(62.5)$ & \multirow{2}{*}{0.407} \\
\hline Female & 798 (39.9) & $48(37.5)$ & \\
\hline BMI $\left(\mathrm{Kg} / \mathrm{m}^{2}\right)$ & $24.8 \pm 2.1$ & $23.2 \pm 3.5$ & 0.663 \\
\hline \multicolumn{4}{|l|}{$\mathrm{DM}$} \\
\hline No & $2034(86.5)$ & $104(81.3)$ & \multirow{2}{*}{0.095} \\
\hline Yes & $318(13.5)$ & $24(18.8)$ & \\
\hline \multicolumn{4}{|l|}{ Type of gastrectomy } \\
\hline Total gastrectomy & $436(18.5)$ & $49(38.3)$ & \multirow{2}{*}{$<0.001$} \\
\hline Subtotal gastrectomy & $1916(81.5)$ & $79(61.7)$ & \\
\hline \multicolumn{4}{|l|}{ Reconstruction } \\
\hline Billroth I & $912(38.8)$ & $32(25)$ & \multirow{3}{*}{$<0.001$} \\
\hline Billroth II & 745 (31.7) & $36(28.1)$ & \\
\hline Roux-en-Y & $695(29.5)$ & $60(46.9)$ & \\
\hline \multicolumn{4}{|l|}{ Extent of dissection } \\
\hline D1+ & $752(32)$ & $36(28.7)$ & \multirow{2}{*}{0.418} \\
\hline D2 & $1600(68)$ & $92(71.3)$ & \\
\hline \multicolumn{4}{|l|}{ Number 12 LN dissection } \\
\hline No & $736(31.3)$ & $23(17.9)$ & \multirow{2}{*}{0.009} \\
\hline Yes & $1616(68.7)$ & $105(82.1)$ & \\
\hline \multicolumn{4}{|l|}{ T stage } \\
\hline pT1 & $1124(47.8)$ & $58(45.3)$ & \multirow{4}{*}{0.384} \\
\hline pT2 & $303(12.9)$ & $17(13.3)$ & \\
\hline pT3 & $254(10.8)$ & $20(15.6)$ & \\
\hline pT4 & $671(28.5)$ & $33(25.8)$ & \\
\hline \multicolumn{4}{|l|}{ LN metastasis } \\
\hline Negative & $1352(57.5)$ & $74(57.8)$ & \multirow{2}{*}{0.941} \\
\hline Positive & $1000(42.5)$ & $54(42.2)$ & \\
\hline \multicolumn{4}{|l|}{ TNM stage } \\
\hline I & $1260(53.6)$ & $62(48.4)$ & \multirow{3}{*}{0.292} \\
\hline II & $331(14.1)$ & $24(18.8)$ & \\
\hline III & $761(32.3)$ & $42(32.8)$ & \\
\hline
\end{tabular}

between these two groups. With respect to types of gastrectomy, the proportion of total gastrectomy was higher in SP group than in SN group. Furthermore, the proportion of Roux-en-Y reconstruction and lymph node dissection in the hepatoduodenal ligament were higher in SP group than in SN group. Depth of invasion, lymph node metastasis, and TNM stage did not differ significantly between the two groups.

3.2. Risk Factors for Gallstones after Gastrectomy. The incidence of gallstone formation is shown in Table 2. The incidence of gallstones was significantly higher after total gastrectomy than after subtotal gastrectomy. Those with Roux-enY reconstruction were more likely to develop gallstones after gastrectomy than those with Billroth I or II reconstruction. Dissection of lymph node 12 correlated significantly with the development of gallstones. There were no significant differences in age, sex, or diabetes mellitus between the two groups. Multivariate analysis using the Cox proportional hazard model was carried out. Roux-en-Y reconstruction was identified as a significant risk factor for gallstones after gastrectomy, along with diabetes mellitus.

3.3. Surgical Treatment for Gallstone Disease after Gastrectomy. Of the 128 patients with gallstones, 59 (46.1\%) underwent surgical treatment for gallstone disease (Table 3 ). Open cholecystectomy (OC) was performed in 30 patients (50.8\%) and laparoscopic cholecystectomy (LC) in 29 patients (49.2\%). There was 1 open conversion case in the LC group due to dense adhesion and bleeding around Calot's triangle. Mean age in the LC group was younger than in the OC group 
TABLE 2: Univariate and multivariate analysis of risk factors for gallstones after gastrectomy.

\begin{tabular}{|c|c|c|c|c|}
\hline & \multirow{2}{*}{ Incidence of gallstones (\%) } & \multirow{2}{*}{ Univariate analysis } & \multicolumn{2}{|c|}{ Multivariate analysis } \\
\hline & & & Odds ratio & $P$ value \\
\hline Age (years) & & 0.105 & $1.021(0.999-1.043)$ & 0.060 \\
\hline \multicolumn{5}{|l|}{ Sex } \\
\hline Male & 4.9 & 0.346 & 1 & \\
\hline Female & 5.7 & & $1.275(0.796-2.043)$ & 0.313 \\
\hline \multicolumn{5}{|l|}{$\mathrm{DM}$} \\
\hline No & 4.9 & 0.110 & 1 & \\
\hline Yes & 7.0 & & $1.862(1.033-3.357)$ & 0.039 \\
\hline \multicolumn{5}{|l|}{ Type of gastrectomy } \\
\hline Total gastrectomy & 10.1 & $<0.001$ & 1 & \\
\hline Subtotal gastrectomy & 3.9 & & $0.669(0.324-3.275)$ & 0.279 \\
\hline \multicolumn{5}{|l|}{ Reconstruction } \\
\hline Billroth I & 3.4 & $<0.001$ & 1 & \\
\hline Billroth II & 4.6 & & $1.383(0.698-2.740)$ & 0.353 \\
\hline Roux-en-Y & 7.9 & & $3.936(2.210-7.009)$ & $<0.001$ \\
\hline \multicolumn{5}{|l|}{ Number 12 LN dissection } \\
\hline No & 3.0 & 0.004 & 1 & \\
\hline Yes & 6.1 & & $0.806(0.486-1.337)$ & 0.404 \\
\hline
\end{tabular}

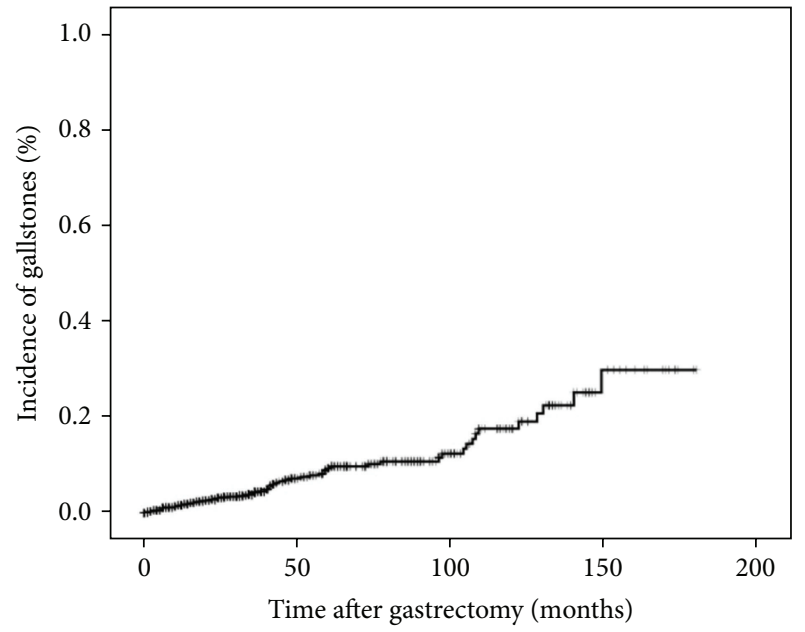

FigURE 2: Incidence of gallstones after gastrectomy.

$(62.3 \pm 2.4$ versus $55.9 \pm 2.2$ years, resp.; $P=0.048)$. However, gender, body mass index, interval between gastrectomy and detection of stones, type of gastrectomy, and reconstruction after gastrectomy were not significantly different between the two groups. Indications of surgery were significantly different. The proportion of silent stone was higher in the LC group than in the OC group, whereas the proportion of common bile duct (CBD) stone or cholangitis is higher in the OC group than in the LC group. The interval between diagnosis of gallstones and cholecystectomy was not different between the two groups $(11.7 \pm 5.5$ versus $11.8 \pm 3.2$ months, resp.; $P=0.936)$. Preoperative management of gallstones, such as percutaneous transhepatic biliary drainage (PTBD), percutaneous transhepatic gallbladder drainage (PTGBD), and endoscopic retrograde cholangiopancreatography (ERCP), was not significantly different between the two groups. CBD exploration was performed more frequently in the OC group than in the LC group. Operation time was shorter in the LC group than in the OC group. LC patients showed shorter hospital stay $(P<0.001)$ and lower incidence of complications $(P=0.003)$.

\section{Discussion}

To date, gallstone management decisions in patients who underwent gastrectomy are dependent only on the surgeon's preference and expertise. Prophylactic cholecystectomy has been proposed, because concomitant cholecystectomy is not time consuming, poses minimal risks for patients, and allows patients to avoid difficult procedures, such as ERCP, during intestinal reconstruction $[9,14-16]$. Others have argued that patients with asymptomatic gallstones develop serious biliary symptoms at a low rate over time; thus, subsequent cholecystectomy after gastrectomy can be performed safely, and the additional calculated morbidity for subsequent cholecystectomy is lower than the morbidity for prophylactic cholecystectomy $[1,2,9,17]$. In this study, $5.2 \%$ of patients undergoing gastrectomy were diagnosed with gallstones during followup, and only half of them required cholecystectomy. Moreover, there were no mortalities or major injuries as a result of a previous gastrectomy. Thus, concomitant cholecystectomy during gastrectomy is not necessary.

In this study, the incidence of gallstones was compared in subgroups of patients classified according to the type of gastrectomy. Gallstone formation was more frequent (10.1 versus $3.9 \%)$ in the total gastrectomy group than in the subtotal gastrectomy group. However, gallstones in the total gastrectomy group did not form earlier or require more frequent surgical treatment than those in the subtotal 
TABLE 3: Surgical treatment for gallstone disease after gastrectomy.

\begin{tabular}{|c|c|c|c|}
\hline & $\begin{array}{l}\text { Open cholecystectomy } \\
\qquad(n=30)\end{array}$ & $\begin{array}{c}\text { Laparoscopic } \\
\text { cholecystectomy } \\
(n=29)\end{array}$ & $P$ value \\
\hline Age (year) & $62.3 \pm 2.4$ & $55.9 \pm 2.2$ & 0.048 \\
\hline \multicolumn{4}{|l|}{ Gender } \\
\hline Male & $21(70)$ & $12(44.8)$ & \multirow[t]{2}{*}{0.077} \\
\hline Female & $9(30)$ & $16(55.2)$ & \\
\hline $\mathrm{BMI}\left(\mathrm{Kg} / \mathrm{m}^{2}\right)$ & $22.6 \pm 3.9$ & $23.8 \pm 3.0$ & 0.204 \\
\hline Interval between gastrectomy and detection of stones (month) & $49.5 \pm 6.9$ & $50.5 \pm 7.8$ & 0.918 \\
\hline \multicolumn{4}{|l|}{ Type of gastrectomy } \\
\hline Total gastrectomy & $14(46.7)$ & $14(48.3)$ & \multirow[t]{2}{*}{0.612} \\
\hline Subtotal gastrectomy & $16(53.3)$ & $15(51.7)$ & \\
\hline \multicolumn{4}{|l|}{ Reconstruction } \\
\hline Billroth I & $4(13.3)$ & $5(17.3)$ & \multirow[t]{3}{*}{0.417} \\
\hline Billroth II & $11(36.7)$ & $7(24.1)$ & \\
\hline Roux-en-Y & $15(50)$ & $17(58.6)$ & \\
\hline \multicolumn{4}{|l|}{ Indication of surgery } \\
\hline Silent stone & $1(3.3)$ & $11(37.9)$ & \multirow[t]{3}{*}{0.001} \\
\hline Cholecystitis & $12(40)$ & $14(48.3)$ & \\
\hline CBD stone or cholangitis & $17(56.7)$ & $4(13.8)$ & \\
\hline Interval between detection of stones and cholecystectomy (month) & $11.7 \pm 5.5$ & $11.8 \pm 3.2$ & 0.936 \\
\hline \multicolumn{4}{|l|}{ Operation } \\
\hline Cholecystectomy & $9(30)$ & $25(86.2)$ & \multirow[t]{2}{*}{$<0.001$} \\
\hline Cholecystectomy and choledochotomy & $21(70)$ & $4(13.8)$ & \\
\hline \multicolumn{4}{|l|}{ Preoperative management } \\
\hline PTBD before cholecystectomy & $1(3.3)$ & $1(3.4)$ & 0.981 \\
\hline PTGBD before cholecystectomy & $2(6.7)$ & $0(0)$ & 0.157 \\
\hline ERCP before cholecystectomy & $6(20)$ & $2(6.9)$ & 0.142 \\
\hline Operation time (min) & $143 \pm 8.8$ & $82.7 \pm 7.1$ & $<0.001$ \\
\hline $\mathrm{EBL}(\mathrm{mL})$ & $218.5 \pm 26.5$ & $140.2 \pm 30.7$ & 0.059 \\
\hline Hospital stay (day) & $10 \pm 0.6$ & $3.9 \pm 0.4$ & $<0.001$ \\
\hline Complications & $9(30)$ & $0(0)$ & 0.003 \\
\hline Postoperative bile leak & $1(3.3)$ & $0(0)$ & \\
\hline Wound infection & $6(20)$ & $0(0)$ & \\
\hline Pulmonary & $2(6.7)$ & $0(0)$ & \\
\hline
\end{tabular}

PTBD = percutaneous transhepatic biliary drainage, PTGBD = percutaneous transhepatic gallbladder drainage, and ERCP $=$ endoscopic retrograde cholangiopancreatography.

gastrectomy group. Destruction of vagal nerves is one of the risk factors for formation of gallstones after gastrectomy $[4,6,7]$. A previous experimental study showed that gastrectomy abolishes phasic contraction of gallbladder bile and mixing of gallbladder bile with fresh hepatic bile, leading to supersaturation and increased gallstone formation [18]. This suggests that complete amputation of the vagal trunk with dissection of the esophagus influences the contractile ability of the gallbladder.

Exclusion of the duodenum during reconstruction is known to be associated with the development of gallstones. Kobayashi et al. suggested that exclusion of the duodenum leads to changes in cholecystokinin secretion, resulting in decreased gallbladder contraction and an increased risk of gallstones [4]. They demonstrated that reconstruction with duodenal exclusion, such as Billroth II or Roux-en-Y, was associated with a significantly higher incidence than was nonexclusion. In this study, Roux-en-Y reconstruction was associated with a significantly higher incidence than Billroth I or II reconstruction. Kobayashi et al. also showed that patients who had lymph node dissection in the hepatoduodenal ligament had a significantly higher incidence of gallstones than those who did not [4]. In this study, patients who had lymph node dissection in the hepatoduodenal ligament had a significantly higher incidence of gallstones than those who did not. However, only Roux-en-Y reconstruction was 
identified as one of significant risk factors for gallstone development.

In this study, there were no severe biliary complications in patients who underwent subsequent cholecystectomy after gastrectomy. One patient in open cholecystectomy group experienced a postoperative bile leak but managed conservatively. In the Cholegas study, 12 patients in the prophylactic cholecystectomy (PC) group and six patients in the standard gastric surgery only (SS) group experienced surgical complications, and only one biliary complication was recorded in the PC group [8]. The study showed no statistical significance in surgical complications, even though surgical complications in the PC group were twice as common as those in the SS group. In contrast, Gillen et al. demonstrated that simultaneous cholecystectomy resulted in a higher morbidity of $0.95 \%$ compared with the calculated additional morbidity of early and late cholecystectomy of $0.45 \%$ [3]. They also suggested that removal of normal acalculous gallbladders during upper GI surgery should be recommended, because late cholecystectomy can be performed safely and has a lower morbidity than simultaneous cholecystectomy.

Laparoscopic cholecystectomy is a minimally invasive technique that has become the standard treatment for cholelithiasis, with many well-known advantages over open cholecystectomy $[2,19]$. However, laparoscopic cholecystectomy is challenging after gastric surgery, because the extensive and dense adhesions around the gallbladder increase the risk of conversion, bile duct injuries, and a longer operation time $[9,15]$. Kwon et al. reported that the conversion rate from laparoscopic to open surgery was $10 \%$, and the overall complication rate was $14 \%$ in patients with a previous gastrectomy who underwent laparoscopic cholecystectomy [17]. Kim et al. analyzed cholecystectomy after gastrectomy and identified the factors related to surgical outcome of these associated procedures [20]. They found that the laparoscopic approach was not related to operation time but was related to a shorter hospital stay, while CBD exploration and laparoscopic surgery were not independently related to the occurrence of complications. In this study, LC group had shorter operation times, lower blood loss, and shorter hospital stays than OC group. These findings might result from more frequent rate of $\mathrm{CBD}$ exploration in the OC group than in the LC group.

There are some limitations of this study. First, there may have been bias in the patient selection, because our data were obtained retrospectively in two institutions. Regional or population distribution differences also cannot be disregarded. Second, we did not routinely perform follow-up ultrasound examination on a periodic basis; therefore, it is possible that the true number of patients with gallstones is higher as CT is recognized as being less accurate than ultrasound in detection of gallstones. Third, indications of surgery were significantly different between the two groups. High proportion of acute cholecystitis and CBD exploration in the OC group may increase the incidence of complications and operation time. Additional well-designed, large cohort studies are needed to clarify this issue.

In conclusion, the incidence of gallstone after gastrectomy was significantly higher in total gastrectomy, Rouxen-Y reconstruction, and lymph node dissection in the hepatoduodenal ligament. Diabetes mellitus and Roux-en$\mathrm{Y}$ reconstruction were significant risk factors for gallstones after gastrectomy in multivariate analysis. Of 128 cases with gallstones that were followed for $91.6 \pm 26.4$ months, 81 patients $(63.3 \%)$ remained asymptomatic. Moreover, only a few postoperative complications occurred after subsequent cholecystectomy, even when using a laparoscopic approach. Thus, prophylactic cholecystectomy might be unnecessary. However, to define more clearly the incidence, risk factors, and surgical outcomes of gallstone after gastrectomy, a controlled prospective clinical trial should be performed.

\section{Conflict of Interests}

The authors report no competing financial interests.

\section{References}

[1] T. Fukagawa, H. Katai, M. Saka, S. Morita, T. Sano, and M. Sasako, "Gallstone formation after gastric cancer surgery," Journal of Gastrointestinal Surgery, vol. 13, no. 5, pp. 886-889, 2009.

[2] G. H. Sakorafas, D. Milingos, and G. Peros, "Asymptomatic cholelithiasis: is cholecystectomy really needed? A critical reappraisal 15 years after the introduction of laparoscopic cholecystectomy," Digestive Diseases and Sciences, vol. 52, no. 5, pp. 1313-1325, 2007.

[3] S. Gillen, C. W. Michalski, T. Schuster, M. Feith, H. Friess, and J. Kleeff, "Simultaneous/incidental cholecystectomy during gastric/esophageal resection: systematic analysis of risks and benefits," World Journal of Surgery, vol. 34, no. 5, pp. 1008-1014, 2010.

[4] T. Kobayashi, M. Hisanaga, H. Kanehiro, Y. Yamada, S. Ko, and Y. Nakajima, "Analysis of risk factors for the development of gallstones after gastrectomy," British Journal of Surgery, vol. 92, no. 11, pp. 1399-1403, 2005.

[5] T. Akatsu, M. Yoshida, T. Kubota et al., "Gallstone disease after extended (D2) lymph node dissection for gastric cancer," World Journal of Surgery, vol. 29, no. 2, pp. 182-186, 2005.

[6] S. Q. Yi, H. Terayama, M. Naito et al., "Surgical anatomy of innervation of the gallbladder in humans and Suncus murinus with special reference to morphological understanding of gallstone formation after gastrectomy," World Journal of Gastroenterology, vol. 13, no. 14, pp. 2066-2071, 2007.

[7] K. Inoue, A. Fuchigami, R. Hosotani et al., "Release of cholecystokinin and gallbladder contraction before and after gastrectomy," Annals of Surgery, vol. 205, no. 1, pp. 27-32, 1987.

[8] M. Bernini, L. Bencini, R. Sacchetti et al., "The Cholegas Study: safety of prophylactic cholecystectomy during gastrectomy for cancer: preliminary results of a multicentric randomized clinical trial," Gastric Cancer, vol. 16, no. 3, pp. 370-376, 2013.

[9] A. Sasaki, J. Nakajima, H. Nitta, T. Obuchi, S. Baba, and G. Wakabayashi, "Laparoscopic cholecystectomy in patients with a history of gastrectomy," Surgery Today, vol. 38, no. 9, pp. 790794, 2008.

[10] H. Yamamoto, N. Hayakawa, T. Yamamoto, M. Momiyama, and M. Nagino, "Laparoscopic cholecystectomy in patients with a previous history of gastrectomy," Hepato-Gastroenterology, vol. 60, no. 123, pp. 443-446, 2013.

[11] W. A. Gracie and D. F. Ransohoff, "The natural history of silent gallstones: the innocent gallstone is not a myth," The New England Journal of Medicine, vol. 307, no. 13, pp. 798-800, 1982. 
[12] C. K. McSherry, H. Ferstenberg, W. F. Calhoun et al., "The natural history of diagnosed gallstone disease in symptomatic and asymptomatic patients," Annals of Surgery, vol. 202, p. 59, 1985.

[13] T. Sano and Y. Kodera, "Japanese classification of gastric carcinoma: 3rd English edition," Gastric Cancer, vol. 14, no. 2, pp. 101-112, 2011.

[14] S. Watemberg, O. Landau, R. Avrahami, I. L. Nudelman, and R. Reiss, "Incidental cholecystectomy in the over-70 age group. A 19-year retrospective, comparative study," International Surgery, vol. 82, no. 1, pp. 102-104, 1997.

[15] S. A. Fraser and H. Sigman, "Conversion in laparoscopic cholecystectomy after gastric resection: a 15-year review," Canadian Journal of Surgery, vol. 52, no. 6, pp. 463-466, 2009.

[16] S. J. Oh, W. B. Choi, J. Song, W. J. Hyung, S. H. Choi, and S. H. Noh, "Complications requiring reoperation after gastrectomy for gastric cancer: 17 Years experience in a single institute," Journal of Gastrointestinal Surgery, vol. 13, no. 2, pp. 239-245, 2009.

[17] A.-H. Kwon, H. Inui, A. Imamura, M. Kaibori, and Y. Kamiyama, "Laparoscopic cholecystectomy and choledocholithotomy in patients with a previous gastrectomy," Journal of the American College of Surgeons, vol. 193, no. 6, pp. 614-619, 2001.

[18] K. Ura, S. K. Sarna, and R. E. Condon, "Antral control of gallbladder cyclic motor activity in the fasting state," Gastroenterology, vol. 102, no. 1, pp. 295-302, 1992.

[19] "A prospective analysis of 1518 laparoscopic cholecystectomies. The Southern Surgeons Club," The New England Journal of Medicine, vol. 324, no. 16, pp. 1073-1078, 1991.

[20] J. Kim, J. N. Cho, S. H. Joo, B. S. Kim, and S. M. Lee, "Multivariable analysis of cholecystectomy after gastrectomy: laparoscopy is a feasible initial approach even in the presence of common bile duct stones or acute cholecystitis," World Journal of Surgery, vol. 36, no. 3, pp. 638-644, 2012. 


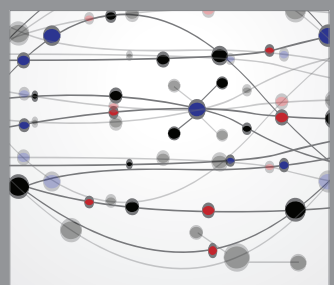

The Scientific World Journal
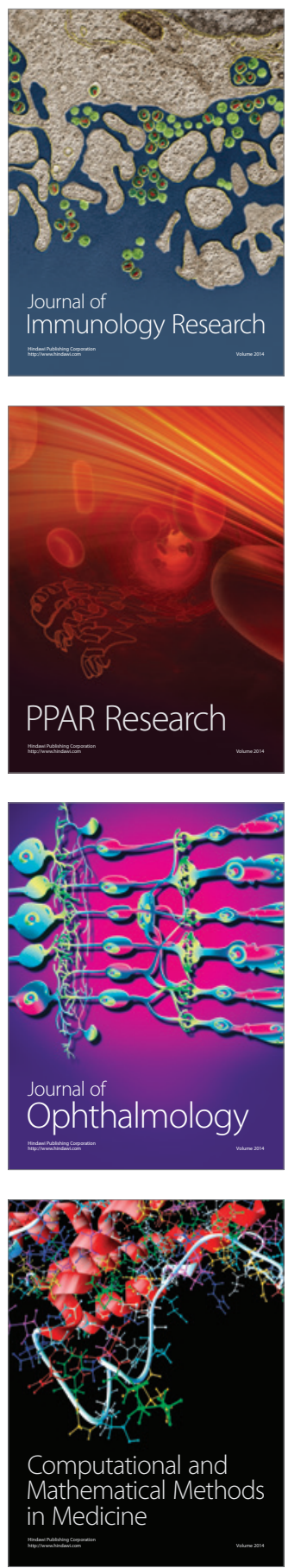

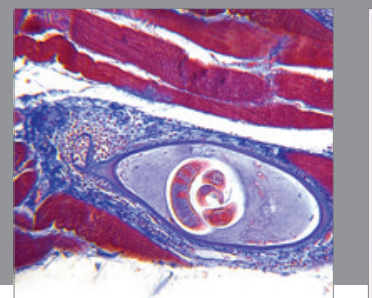

Gastroenterology

Research and Practice
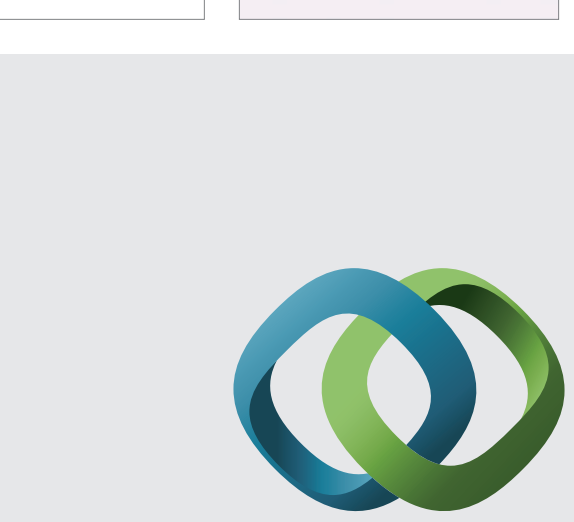

\section{Hindawi}

Submit your manuscripts at

http://www.hindawi.com
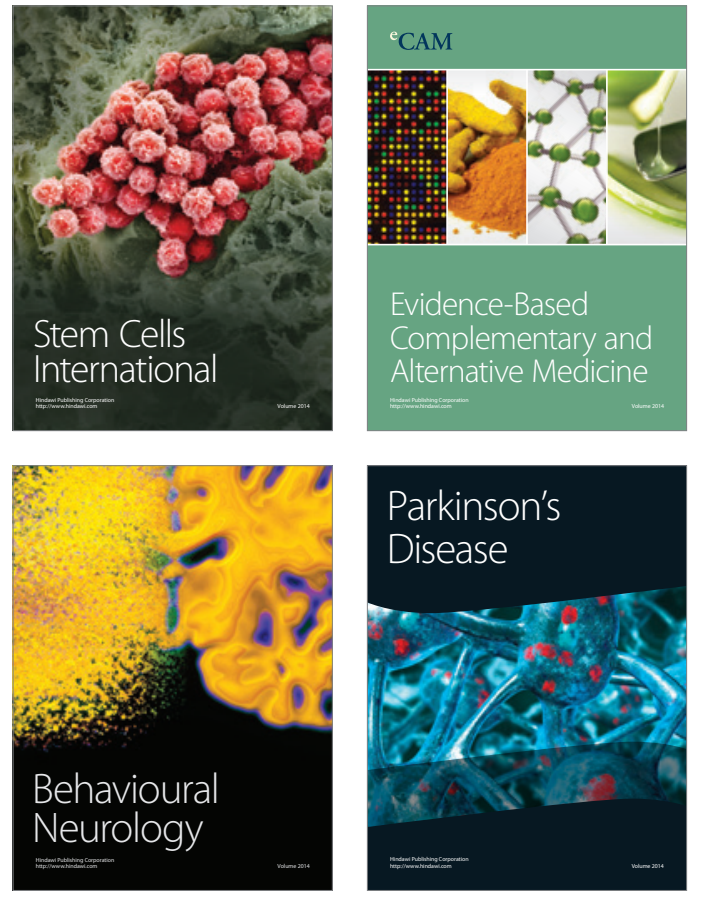
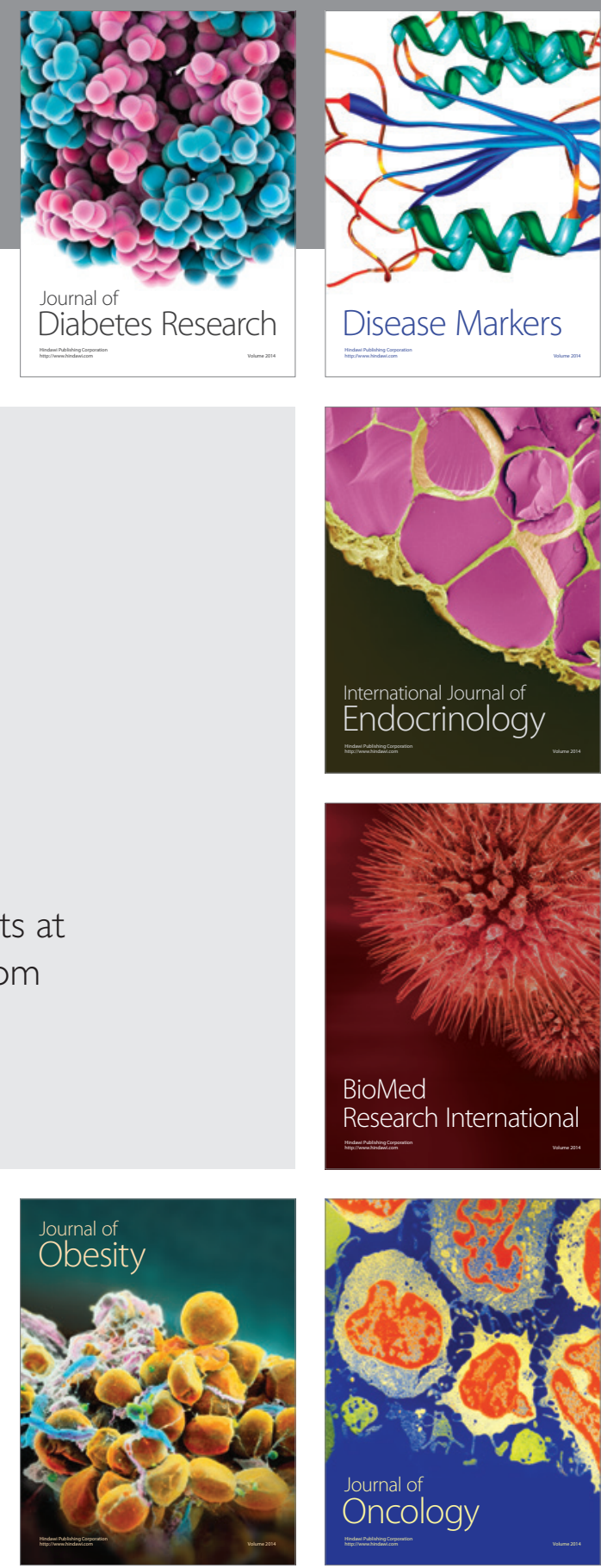

Disease Markers
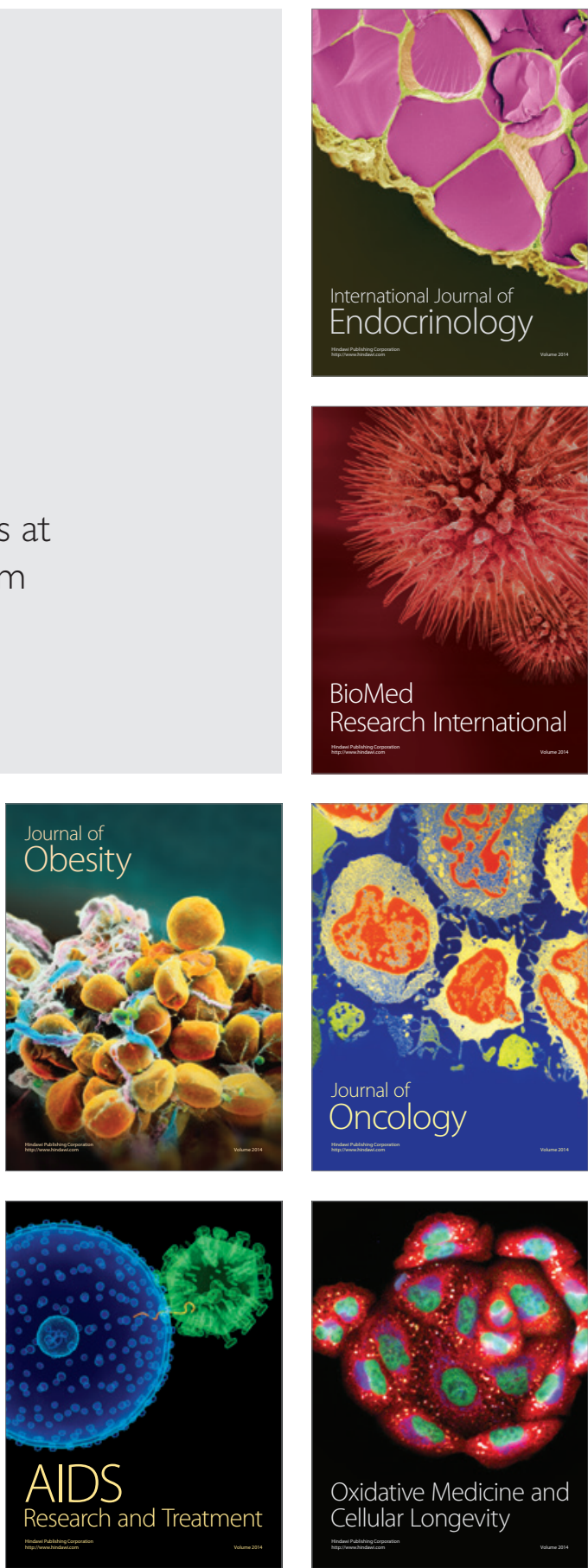